\title{
Growth and ideas in a competitive world:
} A complement

\author{
Vincent Boitier* \\ Department of Economics, Le Mans University, Le Mans, France
}

Received: 20 May 2020

Revised: 13 November 2020

Accepted: 13 January 2021

\begin{abstract}
In this short article, I build an idea-based growth model in a competitive market with a representative household economy. I obtain significant findings that confirm Boitier (2019). First, contrary to conventional wisdom, a competitive equilibrium, increasing returns to scale, and innovations can be tenable. For that, firms must raise capital from shareholders, and the production function must show decreasing returns to scale in the stock of ideas and in labor. Second, the developed idea-based growth model admits a balanced growth path similar to the one provided in an idea-based growth model with monopolistic competition. Whether innovations are competitive or thrive under monopolistic competition does not constitute an engine-driving long-run growth.
\end{abstract}

Keywords: growth theory; ideas; increasing return to scale; competitive equilibrium JEL Classification Codes: E13, O31, O33

\section{Introduction}

In a recent article, Boitier (2019) builds an idea-based growth model with competitive markets and finds two strong points:

i)- a competitive equilibrium, increasing returns to scale, and innovations are compatible if firms raise capital from shareholders, and if the production function shows decreasing returns to scale in the stock of ideas and in labor

ii)- the idea-based growth model with competitive markets admits a balanced growth path similar to the one provided in an idea-based growth model with monopolistic competition

Result i)- is relevant because it runs against conventional wisdom: increasing returns to scale (due to ideas) and competition can be tenable. Result ii)- is insightful because it establishes that innovations thriving under perfect competition are not detrimental to the dynamics of the economy. Whether ideas are competitive or not does not appear to provide a specific explanation for long-run growth. This reduces the conflict between two segments of the literature (Romer (1990, 2015) versus Boldrin and Levine (2008)). However, these results are

\footnotetext{
*E-mail: vincent.boitier@univ-lemans.fr.
}

Citation: Boitier, V. (2021) Growth and ideas in a competitive world: A complement, Economics and Business Letters, 10(2), 157-163.

DOI: $10.17811 /$ ebl.10.2.2021.157-163 
derived from a worker-capitalist model that constitutes a specific ownership structure. In this technical note, I show that i)- and ii)- continue to be held in a standard framework: in the representative household economy.

The rest of the paper is organized as follows. Section 2 introduces the model. Section 3 provides the conclusions.

\section{Growth, ideas and competition}

\subsection{Environment}

Next, I develop the setting of Boitier (2019) in the representative household economy.

\subsubsection{Time and technology}

Time is continuous and denoted by $t \geq 0$. The economy is populated by a mass $h$ of households that are workers or researchers. The population of households grows at a constant $n>0$ in a such way that:

$$
h_{t}=h_{0} e^{n t}, \quad h_{0}>0
$$

The economy is also populated by many identical firms. The behavior of these firms is summarized by a representative firm. The latter is reduced to a technology that happens to be defined as follows:

$$
Y=F(A, K, L)
$$

with $Y$ being production, $A$ being ideas (or knowledge), $L$ being labor, and $K$ being capital. ${ }^{1} F$ is assumed to be defined on $\mathbb{R}_{+}^{3}$, continuous, twice differentiable, strictly increasing, and concave in each argument. $F$ is also homogeneous of degree 1 in the input subset $(K, L)$. This means that the Euler theorem applies. Constant returns to scale in rival inputs exhaust the output if rival factors of production are paid to its marginal products. In accordance with Romer (1990), $F$ is also assumed be homogeneous of degree $\psi$ with $\psi>1$. This entails that considering the productive effect of ideas, the production function globally exhibits increasing returns to scale.

\subsubsection{Workers and Researchers}

At each point in time, workers inelastically supply one unit of labor to firms in a competitive market for the wage rate $w$. As the labor market is perfectly competitive, there is no unemployment in equilibrium, so the labor market clearing condition is simply:

$$
h_{t}^{W}=L_{t}, \quad L_{0}>0
$$

with $h^{W}$ being the number of workers in the economy. Without loss of generality, $h^{W}$ is defined as:

$$
h_{t}^{W}=\varsigma h_{t}, \quad 0<\varsigma<1
$$

Equivalently, at each point in time, researchers provide $a$ units of ideas to firms in a competitive market for the price rate $p_{A}$. As the researcher sector is perfectly competitive, there is no unemployment in equilibrium and the following constraint is satisfied:

$$
a_{t} h_{t}^{A}=A_{t}, \quad A_{0}>0
$$

where $h^{A}$ is the number of researchers in the economy. A consequence of (4) is that:

$$
h_{t}^{A}=(1-\varsigma) h_{t}
$$

Following Jones (2005), the dynamics of ideas is driven by:

$$
\dot{A}_{t}=v A_{t}^{\phi}\left(h_{t}^{A}\right)^{\kappa}, \quad v>0
$$

with $0<\phi<1$ and $\kappa<1$.

\footnotetext{
${ }^{1} L$ and $K$ are rival inputs, whereas $A$ is considered as a non-rival and partially excludable input (see Romer [1990]). See Section 2.4 for a discussion about of the viability of knowledge.
} 


\subsubsection{Capital dynamics, ownership structure and the representative firm's problem}

The dynamics of the stock of capital is driven by:

$$
\dot{K}_{t}=S_{t}-\delta K_{t}, \quad K_{0}>0
$$

where $S$ are savings and satisfy the good market clearing condition as follows:

$$
Y_{t}=S_{t}+C_{t}
$$

and where $\delta$ is the constant rate of depreciation of physical capital. Moreover, workers and researchers own the capital stock and direct the representative firm. Households are entitled to an identical share of the representative firm and receive a fraction of the profit. Within this environment, the revenue of the household $i$ in $t$ is defined as follows:

$$
\mathcal{J}_{i, t}=w_{t} 1_{i}^{W}+p_{A, t} a_{t} 1_{i}^{A}+\Omega_{t} \mathcal{J}_{t}^{\mathcal{O}}
$$

with $\Omega_{t}=\frac{1}{h_{t}}$ the share dedicated to household $i$ in $t$,

$$
\begin{gathered}
1_{i}^{W}= \begin{cases}1 & \text { ifhouseholdiisaworker } \\
0 & \text { otherwise }\end{cases} \\
1_{i}^{A}= \begin{cases}1 & \text { ifhouseholdiisaresearcher } \\
0 & \text { otherwise }\end{cases}
\end{gathered}
$$

and $\mathcal{J}_{t}^{\mathcal{O}}$ is the revenue from ownership. As in Boitier (2019), the owners make a capital investment, while the representative firm raises capital from their shareholders and generates profits (or dividends). In that case, the revenue from ownership is $\mathcal{J}^{\mathcal{O}}=\Pi$, where the profits $\Pi$ are defined as the income streams that are left over after paying researchers for ideas and giving wages to workers. The profit function of the representative firm is, therefore, expressed as $\Pi=$ $F(A, K, L)-p_{A} A-w L$, which is the "normal" profit that remunerates the productive effect of capital. The return on capital is determined by the rate of profit denoted by $\tilde{R}$ and given by $\tilde{R}=$ $\frac{\Pi}{K} . \tilde{R}$ measures the return per used capital that owners can withdraw to ownership after paying other inputs. Consequently, this implies the following $\mathcal{J}_{t}^{\mathcal{O}}=\widetilde{R}_{t} K_{t}$.

Within this construct, the representative firm's maximizing problem is as follows:

$$
\max _{A_{t}^{d}, L_{t}^{d}}\left\{F\left(A_{t}, K_{t}, L_{t}\right)-p_{A, t} A_{t}-w_{t} L_{t}\right\}
$$

with $p_{A, t}$ and $w_{t}$ being treated as given. Therefore, the decision in terms of capital is binary and given by the following policy rule:

$$
\left\{\begin{array}{l}
\text { if } \tilde{R}_{t}>0 \text { then } K_{t}>0 \\
\text { otherwise } K_{t}=0
\end{array}\right.
$$

If capital yields a positive return $\tilde{R}>0$, then it is used to produce. Conversely, if capital generates the losses $\widetilde{R}<0$, then it is left idle.

\subsubsection{Consumption and the representative household's problem}

Workers and researchers share the same behavior in terms of consumption. They derive the utility $\mathcal{U}$ from consuming a homogeneous good produced in a single industry. $\mathcal{U}$ is of the form:

$$
u=\int_{0}^{\infty} u\left(C_{t}\right) e^{-\rho t} d t
$$

with $C$ being consumption, $\rho>0$ being the preference for the present, and where $u$ is assumed to be defined on $\mathbb{R}_{+}$, which is continuous, twice differentiable, strictly increasing, and concave. In that case, the decision in terms of consumption and saving can be characterized by a representative household that maximizes the following:

$$
\int_{0}^{\infty} h_{t} u\left(c_{t}\right) e^{-\rho t} d t
$$

under the following budget constraint and the following standard transversality condition : 


$$
\dot{v}_{t}=\left(r_{t}-n\right) v_{t}+w_{t} \varsigma+p_{A, t} a_{t}(1-\varsigma)-c_{t}, \lim _{t \rightarrow \infty} v_{t} \exp \left\{-\int_{0}^{t}\left(r_{s}-n\right) d s\right\} \geq 0, \quad v_{0}=v
$$

where $v_{t}$ is the financial wealth of an individual in $t$ and $r_{t}$ is the interest rate in $t$. As usual, capital and loans are perfect substitutes in such a way that $r=R-\delta$, the interest rate is equal to the net rate of capital return.

\subsection{Equilibrium}

Under the environment of Section 2.1, a competitive equilibrium is defined as follows.

Definition 1 A competitive equilibrium fulfills the following conditions:

i)- the representative household maximizes (16) subject to (17)

ii)- the representative firm maximizes (13) and capital is allocated according to (14)

iii)- all markets clear: (3), (5), and (9) are verified

iv)- the dynamics of the economy are summarized by (1), (7), and (8)

\subsection{Results}

The results of Boitier (2019) continue to hold under Section 2.1.

\section{Proposition 1 I obtain the following:}

i)- a unique competitive equilibrium, as exposed in Definition 1, exists if and only if $F$ is homogeneous of degree $0<\varphi<1$ in the input subset $(A, L)$

ii)- if $F$ is Cobb-Douglas:

$$
F(A, K, L)=A^{\theta} K^{\alpha} L^{\beta}, \quad \alpha, \beta, \theta>0, \alpha+\beta=1, \alpha>\theta
$$

and $u$ is CRRA:

$$
u(c)=\frac{c^{1-\zeta}-1}{1-\zeta}, \quad \zeta>0
$$

then the idea-based growth model with competitive markets admits a balanced growth path similar to the one provided in an idea-based growth model with monopolistic competition.

Result i)- states that increasing returns to scale (owing to endogenous innovations) can be compatible with a competitive equilibrium. This runs against conventional wisdom. The intuition for this unexpected result is easy to grasp. When capital is allocated as a loan, it is well acknowledged that ideas and a competitive equilibrium are untenable (see Romer (1990) and Jones (1995)). This is because the firm's maximization program is no longer concave (see Cornet (1988)). In contrast, when capital is allocated from shareholders, a competitive equilibrium can survive. Even if $F$ exhibits increasing returns to scale, the firm's maximization problem (13) remains concave if the production function shows decreasing returns to scale in the stock of ideas and in labor. To see that, note that the following holds in equilibrium: ${ }^{2}$

$$
p_{A}^{*}=F_{A}^{\prime}, \quad w^{*}=F_{L}^{\prime}, \quad 0<\tilde{R}^{*}=\frac{(1-\varphi) F}{K}<F_{K}^{\prime}
$$

Labor and knowledge are paid to their marginal products. However, in line with Boitier (2019), capital compensation is positive as $\varphi<1$, but is lower than its marginal product. Also note that the condition $0<\varphi<1$ is not demanding. For example, if $F$ is Cobb-Douglas as in (18), then the condition is simply $\alpha>\theta$. This parameter restriction is consistent with the empirical results. Cameron (1998) reviews the literature and shows that a reasonable value for $\theta$ lies between 0.05 and 0.1 , which is well below the estimated value of the coefficient $\alpha$.

Result ii)- establishes that idea-based growth models with competitive markets and monopolistic competition are equivalent. In particular, the two models generate the same growth rate in the long run denoted by $g^{*}$ and determined as follows:

\footnotetext{
${ }^{2} F_{X}^{\prime}$ denotes the partial derivative of $F$ with respect to the variable $X$.
} 


$$
g^{*}=\frac{\theta \kappa n}{(1-\alpha)(1-\phi)}
$$

The presence of competitive ideas does not constitute a specific force for social dynamics in the long run. Whether innovations are competitive or thrive under monopolistic competition leads to the same long-run growth.

\subsection{Discussions}

The present framework is based on Romer (1990) and Jones (2005) where ideas are perceived as a pure public good. As ideas are a non-rival and partially excludable good, there may be a free rider problem. In turn, this may question the viability of the existence of knowledge in the long run. To overcome this, Chantrel et al. (2012) build a growth model with Cournot imperfect competition and where knowledge is patented. In that case, knowledge is excludable. In addition, under the assumption that knowledge is perfectly substitutable, patents are traded, and Lindahl prices for knowledge emerge in equilibrium. In that sense, Chantrel et al. (2012) say that the market for knowledge mimics competition, whereas the final good needs to be imperfectly competitive. Similarly, Marchese and Privileggi (2020) develop a continuous time dynamic model where knowledge is a nonrival but excludable good, and where a competitive market is associated to the existence of Lindahl prices. They obtain competitive innovation under demanding conditions (including no wages and no labor market). A key ingredient in their model is that labor is remunerated less than the value of its marginal product. A similar phenomenon occurs in the present framework. As capital is raised by shareholders, it is demonstrated that capital is compensated less than its marginal product.

\section{Conclusion}

In this note, I show that the findings of Boitier (2019) still hold in the representative household economy. Contrary to conventional wisdom, a competitive equilibrium, increasing returns to scale, and innovations can be tenable. For that, firms must raise capital from shareholders, and the production function must show decreasing returns to scale in the stock of ideas and in labor. In addition, the developed idea-based growth model admits a balanced growth path similar to the one provided in an idea-based growth model with monopolistic competition. In particular, whether innovations are competitive or thrive under monopolistic competition does not constitute an engine-driving long-run growth.

\section{References}

Boitier V. (2019) Growth and ideas in a perfectly competitive world, Structural Change and Economic Dynamics, to appear.

Boldrin M., and Levine D. (2008) Perfectly competitive innovation, Journal of Monetary Economics, 55, 435-53.

Cameron G. (1998) Innovation and growth: a survey of the empirical evidence, Nuffield College, Oxford, 1-34.

Chantrel E., Grimaud A., and Tournemaine F. (2012) Pricing knowledge and funding research of new technology sectors in a growth model, Journal of Public Economic Theory, 14, 493 520.

Cornet B. (1988) General Equilibrium Theory and Increasing Returns: Presentation, Journal of Mathematical Economics, 17, 103-118.

Jones C. (2005) Growth and Ideas, Handbook of Economic Growth, in: P. Aghion and S.Durlauf, eds., Amsterdam, North-Holland.

Marchese C., and Privileggi F. (2020) A competitive idea-based growth model, Economics of Innovation and New Technology, 29, 313-330. 
Romer P. (2015) Mathiness in the Theory of Economic Growth, American Economic Review: Papers and Proceedings, 105, 89-93

Romer P. (1990) Endogenous Technological Change, Journal of Political Economy, 98, S71S102.

\section{Appendix A - Proofs}

Proof 1 To show the existence of a unique competitive equilibrium, it is sufficient to prove that (13) is well-defined, and profits are strictly positive in equilibrium. Assume that that $F$ is homogeneous of degree $0<\varphi<1$ in the input subset $(A, L)$. It immediately follows that (13) is concave and admits a unique solution such that:

$$
p_{A}^{*}=\frac{\partial F(A, K, L)}{\partial A} \quad \text { and } \quad w^{*}=\frac{\partial F(A, K, L)}{\partial L}
$$

In addition, as $F$ is homogeneous of degree $0<\varphi<1$ in the input subset $(A, L)$, the Euler theorem gives:

$$
\varphi F(A, K, L)=\frac{\partial F(A, K, L)}{\partial A} \times A+\frac{\partial F(A, K, L)}{\partial L} \times L
$$

Likewise, as $F$ is also homogeneous of degree 1 in the input subset $(K, L)$, it can be stated that:

$$
F(A, K, L)=\frac{\partial F(A, K, L)}{\partial K} \times K+\frac{\partial F(A, K, L)}{\partial L} \times L
$$

Using the previous relationships, the equilibrium profit function satisfies:

$$
\Pi=(1-\varphi) F(A, K, L)
$$

$\Pi$ is strictly positive as $\varphi<1$.

Then, dividing by $K_{t}$, the dynamics of capital is:

$$
\frac{\dot{K}_{t}}{K_{t}}=s A_{t}^{\theta} k_{t}^{\alpha-1}-\delta
$$

with $k_{t}=\frac{K_{t}}{L_{t}}$. Taking $\operatorname{logs}$ and derivatives of $k_{t}$ gives:

$$
\frac{\dot{k}_{t}}{k_{t}}=s A_{t}^{\theta} k_{t}^{\alpha-1}-(\delta+n)
$$

Along a balance growth path, solving the above equation for $k_{t}$ leads to:

$$
k_{t}^{*}=\left[\frac{s A_{t}^{* \theta}}{n+\delta+g^{*}}\right]^{\frac{1}{1-\alpha}}
$$

with $\frac{\dot{k}_{t}^{*}}{k_{t}^{*}}=g_{k}=g^{*}$ and where $k_{t}^{*}$ and $A_{t}^{*}$ are elements characterized along a balanced growth path. Let $y_{t}=\frac{Y_{t}}{L_{t}}$ be the output per capita. After simple computations, it is easy to obtain the following:

$$
y_{t}=A_{t}^{\theta} k_{t}^{\alpha}
$$

Along a balance growth path, the equation becomes as follows:

$$
y_{t}^{*}=\left[\frac{s}{n+\delta+g^{*}}\right]^{\frac{\alpha}{1-\alpha}} A_{t}^{*} \frac{\theta}{1-\alpha}
$$

Taking logs and derivatives of $y_{t}^{*}$ gives the following:

$$
g^{*}=\frac{\dot{y}_{t}^{*}}{y_{t}^{*}}=\frac{\theta}{1-\alpha} \frac{\dot{A}_{t}^{*}}{A_{t}^{*}}
$$

Noting $h^{A}=(1-\varsigma) h$, along the balance growth path, $A_{t}^{*}$ is given by: 


$$
A_{t}^{*}=\left(\frac{v}{g_{A}^{*}}\right)^{\frac{1}{1-\phi}}\left[(1-\varsigma) h_{0} e^{n t}\right]^{\frac{\kappa}{1-\phi}}
$$

with $g_{A}^{*}=\frac{\dot{A}_{t}^{*}}{A_{t}^{*}}$ Taking $\operatorname{logs}$ and derivatives of $A_{t}^{*}$ yields:

$$
g_{A}^{*}=\frac{\kappa n}{1-\phi}
$$

and so the following holds:

$$
g^{*}=\frac{\theta \kappa n}{(1-\alpha)(1-\phi)}
$$

Last, the FOC for the representative consumer's program is:

$$
\frac{\dot{c}_{t}}{c_{t}}=\frac{1}{\zeta}\left(\tilde{R}_{t}-\delta-\rho\right)
$$

Evaluating the above equation at a balanced growth path gives:

$$
g^{*}=\frac{1}{\zeta}\left[(\alpha-\theta) A_{t}^{*} k_{t}^{* \alpha-1}-\delta-\rho\right]
$$

Noting that $s^{*} A_{t}^{*} k_{t}^{* \alpha-1}=n+\delta+g^{*}$, the equilibrium investing rate along a balanced growth path is determined by:

$$
s^{*}=\frac{(\alpha-\theta)\left(n+g^{*}+\delta\right)}{\rho+\delta+\zeta g^{*}}
$$

Now, consider a standard idea-based growth model with monopolistic competition (see Jones (2005)). In that case, it can be readily demonstrated that the economy admits a unique BGP determined by the following:

$$
\begin{gathered}
y_{t}=\left(\frac{s}{n+\delta+g}\right)^{\frac{\alpha}{1-\alpha}} A_{t}^{\frac{\theta}{1-\alpha}} \\
A_{t}=\left(\frac{v}{g_{A}}\right)^{\frac{1}{1-\phi}}\left[(1-\tau) h_{0} e^{n t}\right]^{\frac{\kappa}{1-\phi}} \\
g_{A}=\frac{\kappa n}{1-\phi} \\
g=\frac{\theta \kappa n}{(1-\alpha)(1-\phi)} \\
s=\frac{\alpha \sigma\left(n+g^{*}+\delta\right)}{\rho+\delta+\zeta g^{*}}
\end{gathered}
$$

with $\theta=\alpha\left(\frac{1}{\sigma}-1\right)$. Up to $\alpha-\theta$ in $s^{*}$ instead of $\alpha \sigma$ in $s$, the BGP under competitive markets is the same as the one obtained under monopolistic competition. $\diamond$ 